\title{
Retraction Note to: Comprehensive gene expression analysis reveals multiple signal pathways associated with prostate cancer
}

Yi Liu ${ }^{1} \cdot$ Hua Song ${ }^{1} \cdot$ Jing Pan $^{2} \cdot$ Jing Zhao ${ }^{3}$

Published online: 18 August 2015

(C) Institute of Plant Genetics, Polish Academy of Sciences, Poznan 2015

Retraction Note to: J Appl Genetics (2014) 55:117-124

DOI 10.1007/s13353-013-0174-9

The Publisher and Editor retract this article in accordance with the recommendations of the Committee on Publication Ethics (COPE). After a thorough investigation we have strong reason to believe that the peer review process was compromised.

The online version of the original article can be found at http://dx.doi.org/ 10.1007/s13353-013-0174-9.

Hua Song

songhua1937@hotmail.com

1 Department of Urology, General Hospital of Jinan Military Command, 25 Shifan Road, Jinan 250031, China

2 Jinan Municipal Center for Disease Control and Prevention, Jinan 250021, China

3 Department of eurology, Jinan Central Hospital affiliated to Shandong University, Jinan 250013, China 